Article

\title{
Evaluating Speed Enforcement Field Set-Ups Used by Regional Police in Belgium: An Analysis of Speed Outcome Indicators
}

\author{
Brenda Wilmots, Elke Hermans, Tom Brijs * and Geert Wets \\ Hasselt University, Transportation Research Institute (IMOB), Agoralaan, 3590 Diepenbeek, Belgium; \\ brenda.wilmots@uhasselt.be (B.W.); elke.hermans@uhasselt.be (E.H.); geert.wets@uhasselt.be (G.W.) \\ * Correspondence: tom.brijs@uhasselt.be; Tel.: +32-11-269-155
}

Academic Editor: Raphael Grzebieta

Received: 26 May 2016; Accepted: 6 December 2016; Published: 23 December 2016

\begin{abstract}
In this paper the results from a field experiment (conducted in 2012) are presented, in which 3 regional police units in the Flemish region of Belgium each tested a particular combination of a speed control (with mobile radar in an anonymous car) with communicative signage. The goal of this paper was to scientifically evaluate frequently used field set-ups. The following set-ups were tested in one week: (1) police unit 1: speed control with and without a static feedback sign placed after the control; (2) police unit 2: speed control with and without a digital feedback sign placed after the control; (3) police unit 3: speed display followed by a second speed display further along the road section. During certain time frames, speed control took place in between both signs. All tested field set-ups generated significant reductions in the speed level. Studying the effect of the different variations for each set-up reveals that the effect of the speed control is generally larger in combination with the signage alongside the road. After the period during which the police activities took place, speed levels again reached their initial level. Based on the before-after analysis, only in police area 2 was a small 'time halo-effect' found. To generalize results from this pilot study, repetition of tested set-ups in the field is recommended as well as testing on a larger scale.
\end{abstract}

Keywords: speed enforcement; speed data; speed control; speed display; field experiment

\section{Introduction}

Speeding-i.e., driving at a speed above the posted speed limit—is considered to be one of the most important risk factors in road safety [1,2]. Numerous research studies show that excessive speed increases the risk of getting involved in a crash as well as the severity of the crash outcome [3-5]. The National Highway Traffic Safety Administration (NHTSA) [6] found that speeding was a contributing factor in 30\% of fatal crashes in the United States in 2012, resulting in 10,219 lives lost in speed-related crashes. As in other European countries, in Belgium speeding is the most common road traffic violation. Given the negative impact of speeding on road safety, e.g. [5], reducing the number of speed violations is an important priority. Speed enforcement is one measure that contributes to reaching this goal.

Overall, current studies on the effectiveness of speed enforcement reveal the positive effects of speed enforcement in terms of speeding behaviour as well as road safety outcomes e.g., [5,7], and more specifically of the use of mobile radars in stationary controls [8,9]. Based on a review of several studies, Thomas et al. [10] conclude that the effects of covert, mobile speed enforcement programs varies from a $20 \%$ to $25 \%$ reduction in the number of daytime casualty crashes. Furthermore, several studies show the effect of enforcement activities on vehicle speed. For example, Champness et al. [11] report a reduction of $6 \mathrm{~km} / \mathrm{h}$ in the average speed during the time that mobile overt speed cameras were operational on $100 \mathrm{~km} / \mathrm{h}$ highways. A review conducted by Elliot and Broughton [12] shows, 
for studies examining the effect of stationary and visible enforcement, a general reduction of 4.8 $\mathrm{km} / \mathrm{h}$ in the mean speed. For stationary and hidden enforcement, the reduction in the average speed varies between 1 and $2.4 \mathrm{~km} / \mathrm{h}$. With regard to more preventative methods used by police, several studies report the positive effects of digital signs alongside the road in terms of a reduction in the travelled speed [13-15]. For example Walter \& Broughton [14] report a decrease in the average speed of $2.25 \mathrm{~km} / \mathrm{h}$ (or $1.4 \mathrm{mph}$ ) when speed indicator devices were in place (on a $30 \mathrm{mph}$ road section).

In this study, we aim to develop greater insight into the effect of a temporary combination of both methods, namely a speed control combined with different types of signage alongside the road. Studies that examine certain combinations are limited [16] and only few studies provide a well-documented overview of the study design which can influence the presented results, e.g., [9,17]. In a study by Woo et al. [18], speed-monitoring displays coupled with enforcement cameras downstream were found to be an effective approach. However the study design in this research differs as we test a more temporary combination of methods. Generally, a combination of a repressive enforcement method (which includes deterring and fining drivers for speeding, e.g., speed control) with the usage of signs alongside the road has been found to be more effective given the fact that (digital) signage raises the visibility of the enforcement activities $[8,16]$. Furthermore, the use of (digital) signage creates a more generalized deterrent effect, as it informs all passing drivers and therefore influences drivers' perceived risk of being caught for speeding. Research in Queensland, Australia, found that more visible enforcement raises self-compliance and creates longer-lasting effects on behavior [19].

Speeding is also in Belgium an important problem and therefore three territorial police units that participated in this research spent a lot of effort and resources on tackling this problem in their area in order to improve the road safety level. Given the fact that currently a scientific evaluation of the effect of frequently used speed enforcement methods is missing, the regional police units are interested in learning more about this in order to improve their strategy.

\section{Materials and Methods}

\subsection{Objectives}

The main goal of this research is to measure the effects of certain repressive and preventative speed enforcement methods used simultaneously at the field (i.e., field set-up). To do so, researchers from Hasselt University worked together with 3 regional police units ('HaZoDi', 'Kempenland' and 'West-Limburg') in the province of Limburg (in the Flemish region of Belgium). Each regional police unit selected a frequently used set-up of a repressive method (speed control) and a preventative method (signage).

The effect of each field set-up was tested (before-after analysis):

- $\quad$ during the time the field set-up was in place (before-during)

- $\quad$ after removal of the field set-up was in place (before-after).

Besides studying the overall effect of each selected set-up, we also compare the effect of tested variations. Based on a literature review, we hypothesize that adding signage as a preventive measure to a repressive control will raise visibility and therefore will generate larger effects in terms of measured speed reductions (compared to a repressive method alone). Furthermore, we assume that drivers exposed to a repressive and preventative method set up simultaneously at the field will be more likely to anticipate the presence of enforcement on subsequent occasions when passing the same site based on [20]. In other words, we hypothesize that a continuing effect (so called 'time halo effect') will more likely be found for a combination of methods, e.g., [14,21]. 


\subsection{Experimental Design}

\subsubsection{Selected Road Sections}

In each police area a suburban arterial road with a speed limit of $70 \mathrm{~km} / \mathrm{h}$ (note: $1 \mathrm{mi}=1.61 \mathrm{~km}$ ) and similar infrastructural features was selected. Each road segment had one lane in each direction (whereby the two lanes were not separated by any kind of median) and had an (adjacent) cycle lane in each direction. Besides similar infrastructural features, these experimental roads were selected because of the existence of a clear speeding problem, the occurrence of speed-related injury crashes, sufficient traffic volume and free-flow conditions (no speed reduction measures, etc.) on at least one section of that road. To study these criteria, existing data were analysed (data on crashes and speed offences), location visits took place and preliminary measurements were conducted taking into account the exact road section in relation to the predetermined set-up at the field.

Since these experimental roads were not randomly selected, the presented experiment can be categorized as a 'quasi-experimental study'. Due to practical reasons (limited number of measurement equipment), no speed measurements on a comparison road took place.

\subsubsection{Measurement Periods and Equipment}

This field experiment was set up in 2012 (period April-May). Table 1 gives an overview of the general timing and duration of the speed measurements.

Table 1. Measurement periods.

\begin{tabular}{lccc}
\hline & & Research Period \\
\hline Period & Before & $\begin{array}{c}\text { During ('experimental' or } \\
\text { 'intervention' period) }\end{array}$ & After \\
\hline Timing & 16 April 2012-23 April 2012 & 23 April 2012-30 April 2012 & 30 April 2012-21 May 2012 \\
\hline Duration & 1 week & 1 week during scheduled hours & 3 weeks \\
\hline
\end{tabular}

Several factors were taken into account when selecting the above measurement periods such as the season/general weather conditions during the period (i.e., winter period was avoided because of possible adverse weather conditions), the holiday periods/school holidays, etc. No unusual conditions such as local events and roadworks were reported by the police during the time of the study.

During the research period, speed was measured by means of so-called 'out-of road devices' that use Doppler-based microwave radars to measure spot speeds (i.e., data on instant speed of vehicles at one point) [22]. All regional police units used a similar, small and unobtrusive device that was installed at the selected measurement point (Figure 1).

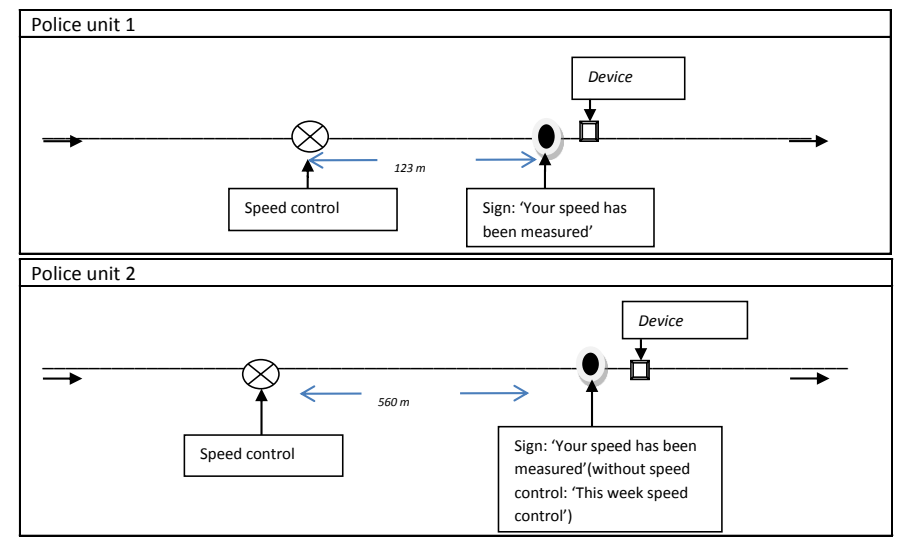

Figure 1. Cont. 


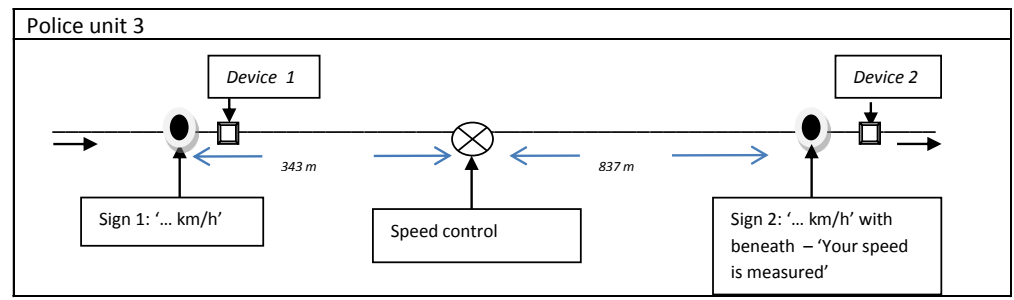

Figure 1. Field set-up for each regional police unit.

\subsubsection{Selected Enforcement Methods and Field Set-Up}

Figure 1 shows for each territorial police force the selected set-up at the field.

It can be seen that the field set-ups tested by police units 1 and 2 are more similar than the combination of signage and speed control tested in police unit 3 . The regional police used a speed control that took place in an unmarked, inconspicuous police car that was manned by one police officer. This car was parked alongside the road, and no interception took place at the field. In the following sections of this paper we simply refer to this method as 'speed control'. This repressive method is frequently used in Belgium, besides the use of fixed radars and upcoming use of automated section speed controls (especially on motorways).

Figure 2 shows the appearance of the different types of signage.
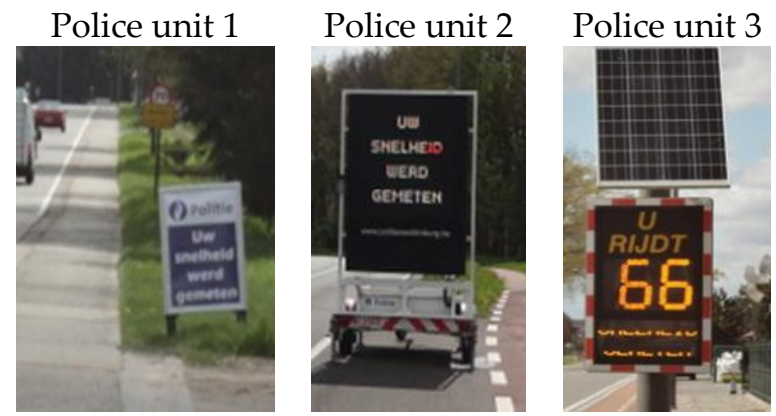

Figure 2. Used signage in the field experiment.

All three set-ups included the use of signage that was located several meters (Note: $1 \mathrm{~m}=1.0936$ yard) from the location of the speed control. As shown in Figure 2 the signs differ in terms of shape and size, digital vs. static, etc. With dimensions of $2.55 \mathrm{~m}$ by $1.70 \mathrm{~m}$ (Note: $1 \mathrm{yd}=0.914 \mathrm{~m}$ ), police unit 2 used the largest signage. The third police unit used two speed displays (see Figure 1).

\subsubsection{Tested Variations during the Intervention Period}

The signage and speed control were not all the time used simultaneously, yet several variations were tested during certain time frames in the intervention period. Time frames during which intensities were not too high (free-flow conditions) or too low (limited sample size) were selected (based on preliminary speed measurement). In accordance with other speed controls conducted in the police area, police officers limited their repressive activities to a maximum of $2 \mathrm{~h}$.

In regional police area 3, no speed control with mobile radar took place on Friday (as opposed to the plan). No other deviations were reported, though the second police unit had missing speed data on Sunday due to an empty battery for the measurement device. Furthermore, it should be noted that in regional police areas 1 and 2 the sign was removed from the field in between the selected time frames. In police area 3, the second digital sign was (for practical reasons) already installed in the beginning of the intervention period (together with the first sign) but was not active until Thursday. 


\subsection{Analysis Methodology}

Speed data were downloaded from the measuring devices, including the date and time as well as the driving speed of each vehicle passing by the measurement point. To exclude slow-moving (and standing) vehicles, vehicle speeds lower than $30 \mathrm{~km} / \mathrm{h}$ were deleted from the data [23]. The following were used as speed indicators (also referred to as 'outcome' or 'effect' indicators): the average speed, the 85th percentile of speed ("V85"), the percentage of (heavy) speed offenders and the odds of drivers (seriously) exceeding the speed limit. To calculate the proportion of speed offenders we take into account the technical margin of $6 \mathrm{~km} / \mathrm{h}$ that is applied in Belgium for speeds lower than $100 \mathrm{~km} / \mathrm{h}$ (www.wegcode.be). For simplicity, we consider speed levels of $7 \mathrm{~km} / \mathrm{h}$ or higher. For serious offences the traveled speed is $10 \mathrm{~km} / \mathrm{h}$ above the speed limit of $70 \mathrm{~km} / \mathrm{h}$ (thus $17 \mathrm{~km} / \mathrm{h}$ higher taking into account the technical margin).

These speed indicators are studied before, during and after each intervention method. To do so, the actual intervention hours (Table 2) were selected from the speed measurements during the research period. For these selected time frames during the day, traffic volumes varied between 250 and 350 vehicles an hour on all experimental roads.

Table 2. Intervention scheme for each regional police unit.

\begin{tabular}{|c|c|c|c|c|c|c|c|}
\hline \multicolumn{8}{|c|}{ Intervention Period } \\
\hline Intervention type & MON & TUE & WED & THU & FRI & SAT & SUN \\
\hline \multicolumn{8}{|c|}{ Police unit 1} \\
\hline Sign & 13:30-15:00 & - & \multirow{2}{*}{$\begin{array}{l}\text { 14:30-16:00 } \\
\text { 10:00-11:30, } \\
\text { 14:30-16:00 }\end{array}$} & - & 10:30-12:00 & - & - \\
\hline Speed control & 13:30-15:00 & - & & - & $10: 30-12: 00$ & - & $14: 00-16: 00$ \\
\hline \multicolumn{8}{|c|}{ Police unit 2} \\
\hline Sign & 13:30-15:00 & - & 10:00-16:00 & - & $10: 30-12: 00$ & - & - \\
\hline Speed control & $13: 30-15: 00$ & - & - & 10:00-11:30 & $10: 30-12: 00$ & - & $14: 00-16: 00$ \\
\hline \multicolumn{8}{|c|}{ Police unit 3} \\
\hline Sign 1 & \multicolumn{7}{|c|}{ Active } \\
\hline Sign 2 & \multicolumn{3}{|c|}{ Present, not active } & \multicolumn{4}{|c|}{ Active } \\
\hline Speed control & - & - & 10:00-11:30 & - & 13:30-15:00 & - & 10:00-12:00 \\
\hline
\end{tabular}

The effect on the 85th percentile speed (not by default included in statistical software) was assessed by analysis in Excel, using the following formula (95\% confidence interval, based on [24]):

$$
\begin{gathered}
E F F=\left(V 85_{l, d u}-V 85_{l, b e}\right) \\
S E_{(\mathrm{EFF})}=\sqrt{S E_{V 85_{l, d u}}^{2}+S E_{V 85_{l, b e}}^{2}}
\end{gathered}
$$

With,

$\boldsymbol{E E F}=$ Estimated effect of speed enforcement measure

$V 85_{l,(b e, d u, a f)}=\mathrm{V} 85$ on location 1 (with enforcement), before-/during-/after-period

$S E=$ standard error

For the other indicators, the significance of effects (95\% confidence interval) is determined by analysis in the IBM Statistical Package for the Social Sciences (SPSS). For the average speed, the proportion of offenders and heavy offenders, an (independent group) $t$-test is performed to interpret the mean difference. Alternatively, this can be expressed by the following linear regression model (for example for the average speed):

$$
y=\beta_{0}+\beta_{1} x_{1}
$$


with $y$ being the average speed and $x_{1}=$ measurement period (dummy variable: before vs. during or after), whereas $\beta_{1}$ shows the size of the effect.

Furthermore, a logistic regression model (binomial distribution and logit link function, SPSS generalized linear model (GENLIN)) was used to estimate the effect on the odds of drivers exceeding the speed limit (or seriously exceeding the speed limit) based on [23]. The dependent variable being $y=\mathrm{P}(\mathrm{A}) /(1-\mathrm{P}(\mathrm{A}))$ gives the ratio of the probability that drivers exceed the speed limit- $\mathrm{P}(\mathrm{A})$-and the probability that drivers do not exceed the speed limit. The measurement period (dummy variable: before vs. during or after) was included as independent variable $\left(x_{1}\right)$ in the model.

The above analyses were also conducted to assess whether or not the effect differs according to the tested variation. Next, the significance of a possible difference in effect between the tested interventions was assessed for each field set-up by means of regression models (SPSS GENLIN procedure). For example, for the odds of drivers exceeding the speed limit in the above model was expanded as follows:

$$
y=\beta_{0}+\beta_{1} x_{1}+\beta_{2} x_{2}+\beta_{3} x_{1} x_{2}
$$

with $y$ being $\mathrm{P}(\mathrm{A}) /(1-\mathrm{P}(\mathrm{A})) ; x_{1}=$ measurement period (dummy variable: before vs. during or after); $x_{2}=$ the tested variation; and $\beta_{3}=$ interaction effect, indicating the significance of the difference in the odds of drivers exceeding the speed limit between both periods (before vs. during or before vs. after) for the considered variations. This interaction effect $\left(\beta_{3}\right)$ was interpreted to determine whether or not differences in effect between variations (e.g., speed control vs. speed control with signage) were statistically significant. Furthermore, for regional police unit 3 we investigate the difference in effect of the speed displays according to time of the day as these displays are active during the day and night (Table 2). A similar model is built (whereby $x_{2}=$ day or night and $\beta_{3}=$ interaction effect), considering the time frame from 6 a.m. to 10 p.m. as 'day' and from 10 p.m. to 6 a.m. as 'night'. This classification is commonly used when analyzing Belgian traffic (crash) data.

\section{Results}

In this section we present the measured effects of the three tested field set-ups (or strategies), each tested by one regional police unit. For each evaluated set-up we first present the overall effect during and after the intervention period in terms of the described indicators. Secondly, we show for each field setup the results of analyzing possible differences in effect between tested variations (e.g., speed control with or without the use of signage).

\subsection{Regional Police Unit 1}

Police unit 1 tested a speed control that was combined with a simple, static display that was placed after the control during some of the scheduled time frames (see Figure 1). The overall effect of the intervention is presented in Table 3. Statistically significant effects were noted with the asterisk * ( $95 \%$ confidence interval).

The above table shows significantly lower values for all outcome indicators during the intervention (all significant at the 0.05 level). For example, the average speed drops by $5.85 \mathrm{~km} / \mathrm{h}$ and the speed level at which $85 \%$ of drivers travel declines by $7 \mathrm{~km} / \mathrm{h}$. The ratio of the probability that drivers exceed the speed limit and the probability that drivers do not exceed the speed limit (odds) decreased (by 67\%) during the enforcement activities. One week after the intervention had ceased, speed indicator values again reached their initial level and are even slightly higher (compared to before) for which no real explanation could be found. Two and three weeks after enforcement we do see lower speed levels compared to the before period, but it is unlikely that this is related to the previous enforcement activities. 
Table 3. Results of the overall effects in regional police unit 1 .

\begin{tabular}{|c|c|c|c|c|c|}
\hline $\begin{array}{l}\text { Effect Compared } \\
\text { to Before }\end{array}$ & $\begin{array}{l}\text { Initial } \\
\text { Value } \\
\text { (Before) }\end{array}$ & During-Before & After 1-Before & After 2-Before & After 3-Before \\
\hline \multirow{3}{*}{$\begin{array}{c}\text { V85 } \\
\text { Average speed } \\
\% \text { speed offenders } \\
\% \text { heavy speed } \\
\text { offenders }\end{array}$} & 78 & $-7[-7.54 ;-6.46]^{* * *}$ & $+1[0.44 ; 1.56]^{* * *}$ & $-1[-1.56 ;-0.44]^{* * *}$ & $-1[-1.55 ;-0.45]^{* * *}$ \\
\hline & 18.58 & $-11.48[-13.54 ;-9.42]^{* * *}$ & $+2.91[0.57 ; 5.25] *$ & $-3.49[-5.71 ;-1.27]^{* *}$ & $-2.73[-4.95 ;-0.50]$ * \\
\hline & 4.88 & $-3.49[4.59 ; 2.38]^{* * *}$ & $+0.65[-0.64 ; 1.96]$ & $-1.89[-3.06 ;-0.72]^{* *}$ & $-0.80[-2.02 ;-0.41]$ \\
\hline $\begin{array}{l}\text { Odds of drivers } \\
\text { exceeding the } \\
\text { speed limit by } \\
\text { more than } \\
10 \mathrm{~km} / \mathrm{h}\end{array}$ & / & $0.28[0.18 ; 0.43]^{* * *}$ & $1.14[0.88 ; 1.49]$ & $0.60[0.44 ; 0.83]^{* *}$ & $0.83[0.62 ; 1.10]$ \\
\hline
\end{tabular}

Notes: ${ }^{*} p<0.05 ;{ }^{* *} p<0.01$; ${ }^{* * *} p<0.001$.

Figure 3 shows for both tested variations (speed control with or without the static display) the absolute effect on the V85 speed and average speed (during vs. before).

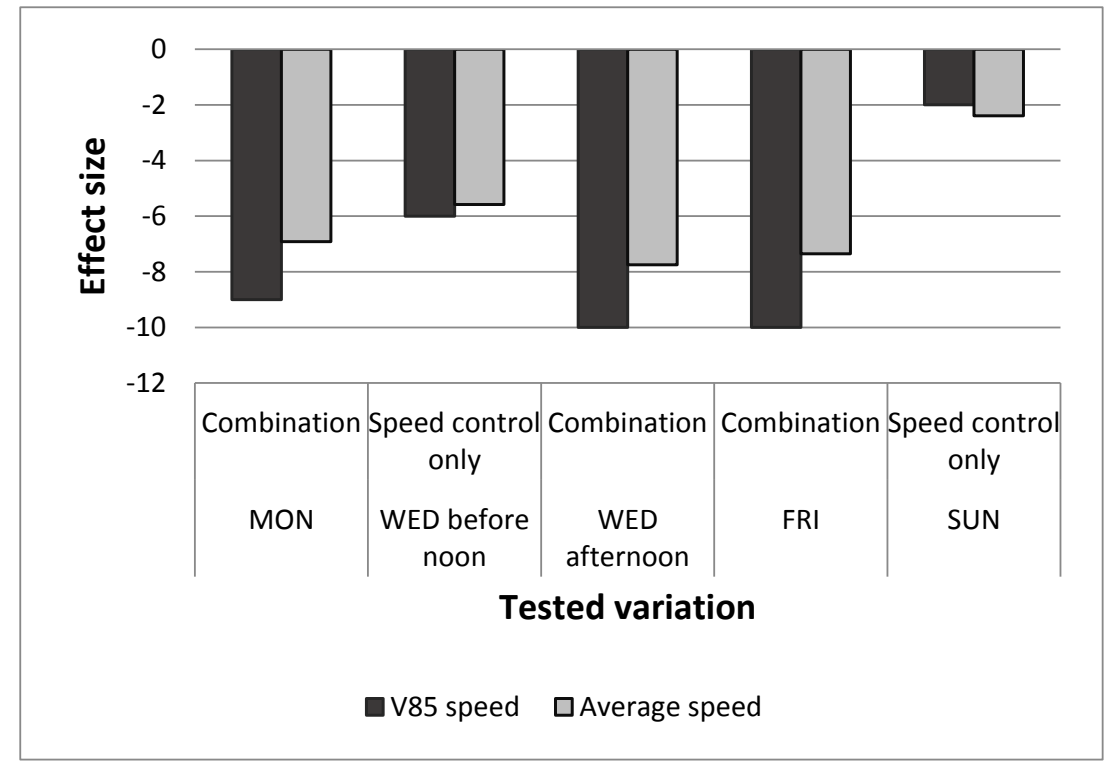

Figure 3. Effects on average speed and V85 speed for 2 types of interventions (regional police unit 1).

Statistical analysis shows that for both variations the reductions in average speed $(-3.65 \mathrm{~km} / \mathrm{h}$ for the speed control only and $-7.34 \mathrm{~km} / \mathrm{h}$ for the combination) are statistically significant. Based on the regression model (GLM) we conclude that the effect of the combination is significantly higher than the effect of the speed control only.

\subsection{Regional Police Unit 2}

In regional police area 2, the effects of a speed control, a digital sign (message 'this week speed control') and a combination of the speed control followed by the digital sign (message 'your speed was measured') were tested (Figure 1). Table 4 shows a high speeding problem on the selected road segment. This might to some extent be affected by a small descending slope in the road. 
Table 4. Results for the overall effects in regional police unit 2.

\begin{tabular}{|c|c|c|c|}
\hline Effect Compared to Before & Initial Value (Before ${ }^{1}$ ) & During-Before $^{1}$ & Before $^{2}$ \\
\hline V85 & 87 & $-7[-7.29 ;-6.71]^{* * *}$ & 87 \\
\hline Average speed & 78.97 & $-5.92[-6.31 ;-5.53]^{* * *}$ & 79 \\
\hline$\%$ speed offenders & 60.18 & $-31.52[-33.76 ;-29.28]^{* * *}$ & 60.3 \\
\hline$\%$ heavy speed offenders & 15.98 & $-12.32[-13.80 ;-10.85]^{* * *}$ & 16.11 \\
\hline $\begin{array}{l}\text { Odds of drivers exceeding the } \\
\text { speed limit }\end{array}$ & / & $0.26[0.24 ; 0.29]^{* * *}$ & / \\
\hline $\begin{array}{l}\text { Odds of drivers exceeding the } \\
\text { speed limit by more than } 10 \mathrm{~km} / \mathrm{h}\end{array}$ & / & $0.20[0.16 ; 0.25]^{* * *}$ & / \\
\hline Effect Compared to Before & After 1-Before $^{2}$ & After 2-Before ${ }^{2}$ & After 3-Before $^{2}$ \\
\hline V85 & $-2[2.28 ;-1.72]^{* * *}$ & $-1[-1.28 ;-0.72]^{* * *}$ & $-1[-1.29 ;-0.71]^{* * *}$ \\
\hline Average speed & $-2.02[-2.41 ;-1.63]^{* * *}$ & $-0.94[-1.32 ;-0.55]^{* * *}$ & $-0.78[-1.18 ;-0.39]^{* * *}$ \\
\hline$\%$ speed offenders & $-8.45[-10.66 ;-6.24]^{* * *}$ & $-3.48[-5.68 ;-1.28]^{* *}$ & $-2.18[-4.38 ;-0.29]$ \\
\hline$\%$ heavy speed offenders & $-4.93[-6.50 ;-3.36]^{* * *}$ & $-2.91[-4.52 ;-1.31]^{* * *}$ & $-2.35[-3.96 ;-0.73]^{* *}$ \\
\hline $\begin{array}{l}\text { Odds of drivers exceeding the } \\
\text { speed limit }\end{array}$ & $0.71[0.65 ; 0.78]^{* * *}$ & $0.87[0.79 ; 0.95]^{* *}$ & $0.91[0.83 ; 1]$ \\
\hline $\begin{array}{l}\text { Odds of drivers exceeding the } \\
\text { speed limit by more than } 10 \mathrm{~km} / \mathrm{h}\end{array}$ & $0.65[0.57 ; 0.75]^{* * *}$ & $0.79[0.70 ; 0.90]^{* * *}$ & $0.83[0.73 ; 0.94]^{* *}$ \\
\hline
\end{tabular}

Notes: ${ }^{*} p<0.05 ; * *<0.01 ; * * *<0.001$. Before ${ }^{1}$ : Including all time frames except on Sunday. During-before ${ }^{1}$ : Excluding Sunday, due to missing data on Sunday during the intervention. Before ${ }^{2}$ : Including all time frames (also on Sunday).

Overall, all indicator values decrease significantly during the tested field set-up (noted with the asterisk *) but the values for the average speed and 85th percentile of speed are still above the legal speed limit. The share of drivers exceeding the speed limit is (roughly) halved and the proportion of serious offences dropped to approximately $3 \%$. The ratio of the probability that drivers exceed the speed limit and the probability that drivers do not exceed the speed limit (odds) decreased by $74 \%$ during the intervention period. Three weeks after the activities had been withdrawn, speed levels gradually increase but are still slightly lower than initially. This indicates the existence of a "time halo effect". Given the high speed levels, these effects found in time are however small and the statistically significant relationship found is mainly due to the large number of observations (making the analysis more sensitive) [25] (e.g., the Cohen's $d$ values vary between 0.1 and 0.2 when comparing the after period with the before period).

Figure 4 shows differences in the effect found for the tested variations (speed control only, digital sign only and combination of both) (during vs. before).

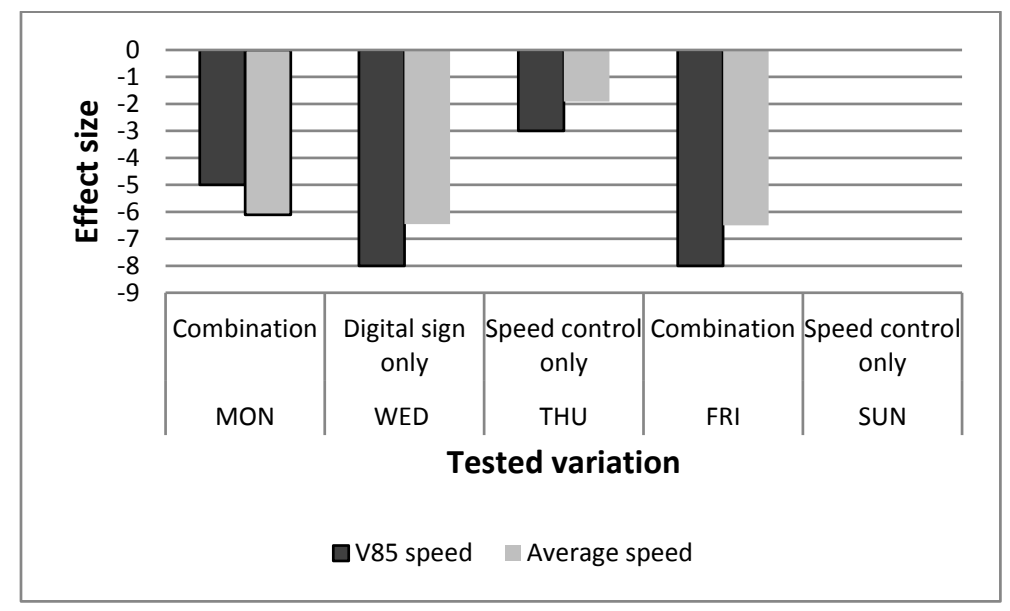

Figure 4. Effects on average speed and V85 speed for 3 types of interventions (regional police unit 2).

The size of the effect on average speed was larger for the combination $(-6.27 \mathrm{~km} / \mathrm{h})$ as well as for the digital sign only $(-6.45 \mathrm{~km} / \mathrm{h})$. The small difference measured in terms of the effect on the average 
speed for these variations was not significant (by interpreting the interaction effect $\beta_{3}$ in the GLM). There was also a significant effect of the speed control only that was significantly lower compared to the other variations.

\subsection{Regional Police Unit 3}

As shown in Figure 1 on the experimental road section in police area 3 the use of two digital signs, with speed control taking place in between the two signs during two time frames, was tested. The first speed display sign displayed the travelled speed and was active during the entire intervention week. The second speed display sign ("...km/h and below "Your speed was measured") was activated later that week and placed further along the road section (see Table 2).

Table 5 shows the effect found at the first measurement point. The asterisk * implies the statistical significance of the effect.

During the week that the speed display was active, it can be observed that the average speed reached a level below the legal speed limit of $70 \mathrm{~km} / \mathrm{h}$ and the proportion of drivers exceeding the speed limit decreased by $9.8 \%$. Furthermore, the proportion of serious offences was halved and the odds of drivers exceeding the speed limit declined by $48 \%$. After the digital sign was removed, speed indicators again reached their initial values.

In contrast to the signage used in the other police areas, the speed displays in police unit 3 were active during day and night. Despite a significant larger effect during the night-e.g., the percentage of speed offenders was significantly reduced from $38.57 \%$ to $26.28 \%(-12.29 \%)$ compared to a significant reduction from $17.70 \%$ to $8.04 \%(-9.66 \%)$ during the day-the speeding problem remains higher during the nighttime. With regard to the day of the week, we see a slightly lower effect in speed reduction on Friday and during the weekend. This might imply that some drivers were surprised by the digital sign at the beginning of the week but were getting used to the sign being there and did not pay any more attention to it towards the end of the week ('novelty effect'). On the other hand, it is possible that the composition of the driver population is different during the weekend and these drivers are less attentive or reactive towards these signage.

Table 5. Results of the overall effects at measurement point 1 in regional police unit 3 .

\begin{tabular}{|c|c|c|c|c|c|}
\hline $\begin{array}{l}\text { Effect Compared } \\
\text { to Before }\end{array}$ & $\begin{array}{l}\text { Initial Value } \\
\text { (Before) }\end{array}$ & During-Before & After 1-Before & After 2-Before & After 3-Before \\
\hline V85 & 80 & $-4[-4.04 ;-3.96]^{* * *}$ & $0[-0.04 ; 0.04]$ & $-1[-1.04 ;-096]^{* * *}$ & $0[-0.04 ; 0.04]$ \\
\hline Average speed & 71.17 & $-2.32[-2.46 ;-2.18]^{* * *}$ & $+0.23[0.09 ; 0.38] * *$ & $-0.44[-0.58 ;-0.29]^{* * *}$ & $+0.06[-0.09 ; 0.21]$ \\
\hline$\%$ speed offenders & 23.91 & $-9.8[-10.37 ;-9.23]^{* * *}$ & $+0.84[0.20 ; 1.48]^{*}$ & $-1.11[-1.72 ;-0.50]^{* * *}$ & $+1.24[0.59 ; 1.89]^{* * *}$ \\
\hline $\begin{array}{l}\% \text { heavy speed } \\
\text { offenders }\end{array}$ & 5.26 & $-2.8[-3.08 ;-2.52]]^{* * *}$ & $+0.42[0.07 ; 0.75]^{*}$ & $-0.10[-0.42 ; 0.22]$ & $+0.81[0.46 ; 1.15]$ \\
\hline $\begin{array}{l}\text { Odds of drivers } \\
\text { exceeding the } \\
\text { speed limit }\end{array}$ & / & $0.52[0.50 ; 0.54]^{* * *}$ & $1.05[1.01 ; 1.08]^{*}$ & $0.94[0.91 ; 0.97]^{* * *}$ & $1.07[1.03 ; 1.11]^{* * *}$ \\
\hline $\begin{array}{l}\text { Odds of drivers } \\
\text { exceeding the } \\
\text { speed limit by more } \\
\text { than } 10 \mathrm{~km} / \mathrm{h}\end{array}$ & / & $0.45[0.42 ; 0.49]^{* * *}$ & $1.08[1.01 ; 1.16]^{*}$ & $0.98[0.92 ; 1.05]$ & $1.16[1.09 ; 1.24]^{* * *}$ \\
\hline
\end{tabular}

Notes: ${ }^{*} p<0.05 ;{ }^{* *} p<0.01 ;{ }^{* * *} p<0.001$.

In Table 6 the effects measured at the second measurement point can be observed for the time period during which the second sign was active (Thursday-Sunday, see Table 2). 
Table 6. Results of the overall effects at measurement point 2 in regional police unit 3.

\begin{tabular}{cccccc}
\hline $\begin{array}{c}\text { Effect Compared } \\
\text { to Before }\end{array}$ & $\begin{array}{c}\text { Initial Value } \\
\text { (Before) }\end{array}$ & During-Before & After 1-Before & After 2-Before & After 3 -Before \\
\hline V85 & 71 & $-4[-4.07 ;-3.93]^{* * *}$ & $0[-0.07 ; 0.07]$ & $-1[-1.07 ;-0.93]^{* * *}$ & $+1[0.92 ; 1.08]^{* * *}$ \\
\hline Average speed & 63.71 & $-2.56[-2.72 ;-2.39]^{* * *}$ & $-0.17[-0.35 ; 0.00$ & $-0.98[-1.16 ;-0.81]^{* * *}$ & $+1.15[0.96 ; 1.34]^{* * *}$ \\
\hline$\%$ speed offenders & 5.93 & $-3.08[-3.50 ;-2.66]^{* * *}$ & $-0.22[-0.70 ; 0.26]$ & $-0.58[-1.05 ;-0.12]^{*}$ & $+1.80[1.24 ; 2.35]^{* * *}$ \\
\hline $\begin{array}{c}\% \text { heavy speed } \\
\text { offenders }\end{array}$ & 1.42 & $-0.66[-0.87 ;-0.44]^{* * *}$ & $+0.14[0.10 ; 0.39]$ & $-0.06[-0.30 ; 0.17]$ & $+0.53[0.25 ; 0.81]^{* * *}$ \\
\hline $\begin{array}{c}\text { Odds of drivers } \\
\text { exceeding the } \\
\text { speed limit }\end{array}$ & $/$ & $0.46[0.42 ; 0.52]^{* * *}$ & $0.96[0.88 ; 1.05]$ & $0.89[0.82 ; 0.98]^{*}$ & $1.33[1.22 ; 1.45]^{* * *}$ \\
\hline $\begin{array}{c}\text { Odds of drivers } \\
\text { exceeding the } \\
\text { speed limit by more } \\
\text { than } 10 \mathrm{~km} / \mathrm{h}\end{array}$ & $/$ & $0.53[0.43 ; 0.66]^{* * *}$ & $1.10[0.93 ; 1.31]$ & $0.95[0.80 ; 1.13]$ & $1.38[1.16 ; 1.64]^{* * *}$ \\
\hline & Notes: ${ }^{*} p<0.05 ; * * 00.01 ; * * *<<0.001$. &
\end{tabular}

The table above shows a significant reduction in all considered speed outcome indicators during the period the second digital sign was active. This even with a speeding problem that is limited (compared to the first measurement point). Looking at the table it can be observed that the proportion of serious offences declined by $3.08 \%$. In accordance with the findings for measurement point one, no clear evidence of a 'time halo effect' could be derived from the data. When considering the speed at the second measurement point earlier in the intervention week (Monday-Wednesday, not displayed in the table above), a small reduction was found in the average speed by $0.98 \mathrm{~km} / \mathrm{h}$ and in the percentage of speed offenders by $1.30 \%$ (both significant at the $95 \%$ confidence level). Given the fact that the second sign was not yet active, this small effect could be explained by the fact that a large number of drivers passed the first sign and consequently still lowered their speed levels over a distance away from that first speed display ('distance halo effect'). Another explanation could be the influence of the physical presence of the sign even though it was not active.

Also for the second digital sign, the size of the effect during nighttime was significantly larger than during the day but the speeding problem remained higher during the night. For the proportion of speed offenders we see for example a reduction from $17.07 \%$ to $12.03 \%$ during the night and from $3.32 \%$ to only $0.38 \%$ during the day (both statistically significant). No difference in effect size was found according to day of the week (Thursday-Sunday).

Finally, we also examined the specific time frames during which speed control took place in between both measurement points. Based on Table 7, we conclude that the effects measured at both measurement points were larger when the speed control was in place (during vs. before).

Table 7. Effect during the speed control in regional police unit 3.

\begin{tabular}{ccccc}
\hline Effect on Average Speed & \multicolumn{2}{c}{ Speed at Measurement Point 1 } & \multicolumn{2}{c}{ Speed at Measurement Point 2 } \\
\hline Period & During the speed control & During the day & During the speed control & During the day \\
WED & $-4.26 \mathrm{~km} / \mathrm{h}$ & $-2.47 \mathrm{~km} / \mathrm{h}$ & $-2.89 \mathrm{~km} / \mathrm{h}$ & $-0.96 \mathrm{~km} / \mathrm{h}$ \\
SUN & $-1.39 \mathrm{~km} / \mathrm{h}$ & $-1.31 \mathrm{~km} / \mathrm{h}$ & $-3.08 \mathrm{~km} / \mathrm{h}$ & $-2.55 \mathrm{~km} / \mathrm{h}$ \\
\hline
\end{tabular}

For measurement point one, the difference on Wednesday $(-4.26 \mathrm{~km} / \mathrm{h})$ is remarkable given the fact that drivers did not yet pass the speed control. Possibly drivers were alerted by vehicles coming from the other direction (e.g., by flashing one's lights). For measurement point two, the effect found on Wednesday could be a distance halo effect given the fact that the second sign was not active at the time. We do note that these time frames are too limited to draw general conclusions. 


\section{Discussion}

\subsection{Synthesis of Findings}

This study examined the speed reduction effects of three field set-ups, which all included the testing of several variations of a speed control with the use of signage alongside a pre-examined road section with a speed limit of $70 \mathrm{~km} / \mathrm{h}$. In accordance to previous studies e.g., [7,8], the tested speed interventions show positive effects in terms of speeding behavior. Examining the global effect shows that all tested set-ups reach the goal of significantly reducing the speed level during the intervention period. Reductions in terms of the average speed and the V85 speed were similar in police area 1 and 2 , where both set-ups included a speed control followed by signage. The tested field set-up in regional police area 3-involving the use of two signs and speed control between both signs-also showed decreases of these outcome indicators. The registered reductions were however lower compared to the other police areas. Even though significant reductions were reached during the intervention period, the speed level remains high on the experimental road in the second police area. We do see a large decline in the proportion of heavy speed offences, which is valuable given the fact that the crash risk increases exponentially as speed increases [26] and the severity of the crash outcome is larger [4]. Comparison of these established effects with related studies should be carried out with care, given the fact that few studies examine combinations of a repressive and preventative method, e.g., [16] and studies differ in terms of study design, characteristics of the enforcement location, etc.

The goal of this study was also to determine if a certain 'time halo effect' could be found. A small continuing effect after enforcement activities had been withdrawn can be found for the tested set-up in regional police area 2 . Besides the high speeding problem-which could make it more likely to find a small effect in time- the large size of the digital sign could have an influence (given the increased visibility). Repetition of the experiment could give more insight into this assumption.

In this study we also examined for each field setup possible differences in effect between the variations of interventions tested. In all cases results point out a higher effect for the speed control combined with signage alongside the road. Consequently we can conclude that in general the hypothesis based on previous research $[8,16]$ is confirmed, showing a larger effect and clear added value of additionally using signage as supporting communication activity on the field. The fact that we do find a smaller, yet significant effect during the speed control only (in police area 1 and 2), implies that some drivers slow down when noticing a parked car alongside the road or possibly recognize the anonymous, unmarked car as a police vehicle. The current field set-ups did not allow the estimation of the effect for each separate intervention used in a particular field set-up, given the fact the multiple variations (e.g., speed control vs. combination) took place within the same intervention period. In other words, the current study design did not allow to test the hypothesis that the use of a preventive method will result in longer lasting effects after activities have been withdrawn $[8,19]$.

\subsection{Practical Implications}

Based on this field experiment we listed following practical implications (to the police units):

- This study demonstrates the added value of combining a repressive speed method with a preventative method.

- There is a clear added value of using signage alongside the road in terms of speed reduction.

- To compare the effects across field set-ups we recommend repetition of the field experiment (see future research). When we look at the established effects in terms of extra costs of buying signage and cost and efforts to exploit it, we note that the static signage used in police unit 1 performs well in terms of effect vs. costs and efforts. The signage is simple to use given the fact that a police officer can set it up himself/herself, while the other tested signs were installed and checked (battery) by the logistics department of the police unit. 
- Unfortunately, the lasting effects of the field set-ups were limited. Only in police area 2 was an effect in time found, which was possibly related to the large visibility of the signage. As mentioned, further research is needed to support this assumption.

- Given the fact that the speed level on the experimental road section in police area 2 remains high (even during police activities), tackling the speeding problem at that road section might require additional measures.

- $\quad$ Though a comparison according to the time of the day (day vs. night) was not the main purpose of this study, the tested field set-up in police unit 3 showed that speed displays also have positive effects during nighttime. During the night these speed displays possibly stand out more. The speed level, however, remains higher during the night as a) drivers generally estimate the risk of getting caught to be lower and b) traffic volumes are low.

The collaboration with the regional police revealed that they are in great need of this kind of information to shape their enforcement policy (in terms of planning and prioritizing speed enforcement activities). Combining scientific knowledge and practical knowledge was valuable. Police units were able to learn more about the effect of frequently used speed enforcement methods by means of an experimental set-up designed by researchers. Since they already apply these methods, limited additional efforts were necessary. For us as researchers, this collaboration was important as it allowed us to conduct an experiment in the real world taking into account the practical possibilities and limitations that come with it (e.g., limited space at the field to place large signage, the need to regularly check or replace the battery of the measurement equipment, etc.). Regular meetings were held to discuss and agree upon the design and the set-up and to interpret the results. Good communication between the researchers and police officers was essential to make sure that the experiment was carried out as planned.

\subsection{Study Limitations}

Looking at the study design and setup at the field, following limitations should be noted with regard to the findings of this study:

- Due to a limited amount of measurement equipment, no speed measurements took place on a comparison road. This is a shortcoming of this study, given the fact that a control group can be useful to correct for general trends and influences such as other speed measures taken in the research period. Given the fact that all measurement periods are short (one week) and adjacent (see Table 1), we do however expect a limited influence of such factors.

- On each location a particular field set-up is tested. To compare the effect of the different field set-ups and enhance the generalizability of these results, replication of the field experiment is recommended. In a first phase, the selected field set-ups could be tested on the other experimental road sections. Also testing on a larger scale would contribute to the generalization of the research results.

- The time frames during which variations were tested within a particular field set-up are limited. Testing these variations over a larger intervention period would be beneficial to exclude that these effects are purely a coincidence. Furthermore, measurement data do not provide insight into the observation and perception of drivers about the presence of speed interventions.

- In each field set-up the measurement device was located right after the signage; for example, in police area 3 a measurement device was situated after each sign. The availability of an extra device in each police area would have been useful. For example, in police area 2, this could have given a better insight in the separate effect of the speed control.

Given these limitations, this experiment was mainly presented to the police units as a pilot which needs repetition to further explore these preliminary findings. Further cooperation between knowledge institutions and field practitioners is therefore advisable. 


\subsection{Future Research}

Despite the fact that road sections with a speed limit of $70 \mathrm{~km} / \mathrm{h}$ and similar infrastructural features were selected, comparison of the effect of each tested field set-up with different interventions remains limited (e.g., 'which type of signage has more effect?'). As mentioned, repetition of this field experiment on a regular basis and larger scale is therefore recommended.

Furthermore, we identified the following research opportunities based on this study:

- The use of automatic registration plate recognition could give some insight into traffic patterns and could also reveal whether or not frequently passing drivers become less attentive to the enforcement measure over time ('novelty effect'). This assumes that the passing vehicles have one main driver.

- To further examine the effect of signage, it would be interesting to stop drivers after passing the signage and question them with regard to the visibility of the sign, their recognition of the message displayed on the sign and their reaction to the message. That way, the effect of different messages using the same signage could be tested. The practicability of such a procedure conducted by police officers on the field should, however, be further investigated. Another methodology is the use of a driving simulation study.

Acknowledgments: We would like to thank the three participating police units ('PZ HaZoDi', 'PZ Kempenland' and 'PZ West-Limburg'). Furthermore, the province of Limburg is acknowledged for their valuable input.

Author Contributions: Brenda Wilmots, Elke Hermans and Geert Wets conceived and designed the experiment together with the police units and the province of Limburg. Brenda Wilmots and Elke Hermans implemented the experimental design and collected and analyzed the data. Tom Brijs contributed to the materials and analysis tools. Brenda Wilmots, Elke Hermans and Tom Brijs wrote the paper.

Conflicts of Interest: The authors declare no conflict of interest.

\section{References}

1. European Transport Safety Council (ETSC). Traffic Law Enforcement across the EU, an Overview; ETSC: Brussels, Belgium, 2006.

2. Global Road Safety Partnership (GRSP). Speed Management: A Road Safety Manual for Decision-Makers and Practitioners; GRSP: Geneva, Switzerland, 2008.

3. Aarts, L.; Van Schagen, I. Driving speed and the risk of road crashes: A review. Accid. Anal. Prev. 2006, 38, 215-224. [CrossRef] [PubMed]

4. Evans, L. Traffic Safety; Science Serving Society: Bloomfield Hills, MI, USA, 2004.

5. Elvik, R.; Høye, A.; Vaa, T.; Sørensen, M. The Handbook of Road Safety Measures, 2nd ed.; Emerald Group Publishing Limited: Bingley, UK, 2009.

6. National Highway Traffic Safety Administration (NHTSA). Traffic Safety Facts Data 2012: Speeding; National Center for Statistics and Analysis: Washington, DC, USA, 2014.

7. DaCoTA. Speed Enforcement; European Commission: Brussels, Belgium, 2013.

8. Erke, A.; Goldenbeld, C.; Vaa, T. Good Practice in the Selected Key Areas: Speeding, Drink Driving and Seat Belt Wearing: Results from Meta-Analysis; European Commission: Brussels, Belgium, 2009.

9. Wilson, C.; Willis, C.; Hendrikz, J.K.; Le Brocque, R.; Bellamy, N. Speed cameras for the prevention of road traffic injuries and deaths. Cochrane Database Syst. Rev. 2010, 11. [CrossRef]

10. Thomas, L.J.; Srinivasan, R.; Decina, L.E.; Staplin, L. Safety effects of automated speed enforcement programs: Critical review of international literature. Transp. Res. Rec. J. Transp. Res. Board 2008, 2078, 117-126. [CrossRef]

11. Champness, P.; Sheehan, M.; Folkman, L.M. Time and distance halo effects of an overtly deployed mobile speed camera. In Proceedings of Road Safety Research, Policing and Education Conference, Wellington, New Zealand, 14-16 November 2005.

12. Elliot, M.; Broughton, J. How Methods and Levels of Policing Affect Road Casualty Rates; Transport Research Laboratory (TRL): Wokingham, UK, 2005.

13. Wrapson, W.; Harré, N.; Murrell, P. Reduction in driver speed using posted feedback of speeding information: Social comparison or implied surveillance? Accid. Anal. Prev. 2006, 38, 1119-1126. [CrossRef] [PubMed] 
14. Walter, L.; Broughton, J. Effectiveness of speed indicator devices: An observational study in South London. Accid. Anal. Prev. 2011, 43, 1355-1358. [CrossRef] [PubMed]

15. Cruzado, I.; Donnell, E.T. Evaluating Effectiveness of Dynamic Speed Display Signs in Transition Zones of Two-Lane, Rural Highways in Pennsylvania. Transp. Res. Rec. J. Transp. Res. Board 2009, 2122, 1-8. [CrossRef]

16. National Highway Traffic Safety Administration (NHTSA). Speed Enforcement Camera Systems. Operational Guidelines; NHTSA: Washington, DC, USA, 2008.

17. Decina, L.E.; Thomas, L.; Srinivasan, R.; Stapling, L. Automated Enforcement: A Compendium of Worldwide Evaluations of Results; National Highway Traffic Safety Administration: Washington, DC, USA, 2007.

18. Woo, T.H.; Ho, S.-M.; Chen, H.-L. Monitoring Displays Coupled with Speed Cameras. Effectiveness on Speed Reduction. Transp. Res. Rec. J. Transp. Res. Board 2007, 2009, 30-36. [CrossRef]

19. Soole, D.; Watson, B.; Lennon, A. The impact of police speed enforcement practices on self-reported speeding: An exploration of the effects of visibility and mobility. In Proceedings of the Australasian Road Safety Research, Policing and Education Conference, Sydney, New South Wales, Australia, 10-13 November 2009; pp. 97-107.

20. Hauer, E. Observational Before-After Studies in Road Safety: Estimating the Effect of Highway and Traffic Engineering Measures on Road Safety; Pergamon Press, Elsevier Science Ltd.: Oxford, UK, 1997.

21. Casey, S.M.; Lund, A.K. The effects of mobile roadside speedometers on traffic speeds. Accid. Anal. Prev. 1993, 25, 627-634. [CrossRef]

22. Hakkert, A.S.; Gitelman, V. Road Safety Performance Indicators: Manual; European Commission: Brussels, Belgium, 2007.

23. De Pauw, E.; Daniels, S.; Brijs, T.; Hermans, E.; Wets, G. Behavioural effects of fixed speed cameras on motorways: Overall improved speed compliance or kangaroo jumps? Accid. Anal. Prev. 2014, 73, 132-140. [CrossRef] [PubMed]

24. Nuyts, E. Methode om Het Effect van een Verkeersveiligheidsmaatregel op de Gemiddelde Snelheid en op de V85 te Berekenen; Steunpunt Verkeersveiligheid: Diepenbeek, Belgium, 2006. (In Dutch)

25. Hair, J.F.; Anderson, R.E.; Tatham, R.L.; Black, W.C. Multivariate Data Analysis; Prentice Hall: Upper Saddle River, NJ, USA, 1998.

26. Nilsson, G. Traffic Safety Dimensions and the Power Model to Describe the Effect of Speed on Safety; Lund Institute of Technology: Lund, Switzerland, 2004.

(C) 2016 by the authors; licensee MDPI, Basel, Switzerland. This article is an open access article distributed under the terms and conditions of the Creative Commons Attribution (CC-BY) license (http://creativecommons.org/licenses/by/4.0/). 